\title{
Mulheres na Assembleia de Deus: para se pensar a categoria gênero além do estruturalismo'
}

\author{
Women in the Assembly of God: \\ to think about the gender category beyond structuralism
}

Ana Luiza Gouvêa Neto

RESUMO

O presente ensaio tem como objetivo discutir a possibilidade de compreender a mulher na Assembleia de Deus a partir de uma perspectiva de gênero pós-estruturalista. Para tanto, o principal marco teórico utilizado será Judith Butler, o qual permite vislumbrar as categorias de sexo, gênero e corpo de forma mais plástica. Não obstante, também serão trazidos à discussão Talal Asad e Marilyn Strathern que somados a Butler, impulsionam reflexões críticas acerca da construção dos conceitos, chamando atenção para a historicidade, para as relações sociais, para o poder e para as normas, nos quais os conceitos estão condicionados.

PALAVRAS-CHAVE: Gênero; Judith Butler; Pós-estruturalismo.

ABSTRACT

This essay aims to discuss the possibility of understanding the woman in the Assembly of God from a poststructuralist gender perspective. Thus, the main theoretical framework used is Judith Butler, which provides a glimpse of the categories of sex, gender and body of more plastic form. Nevertheless, will also be brought to discussion Talal Asad and Marilyn Strathern which added Butler, drive a critical reflections about the construction of concepts, drawing attention to the historicity, for social relations, for power and for the standards, in which the concepts are conditioned.

KEYWORDS: Gender; Judith Butler; Post-structuralism.

${ }^{1}$ Recebido em 01/10/2015. Aprovado em 01/02/2016.

2 Doutoranda em Ciência da Religião pelo Programa de Pós-Graduação em Ciência da religião da Universidade Federal de Juiz de Fora, Juiz de Fora (MG). E-mail: analul72@ hotmail.com 


\section{Introdução}

A Igreja Assembleia de Deus ${ }^{3}$ figura no cenário brasileiro atual como a maior igreja pentecostal do país ${ }^{4}$. Tendo em vista sua expansão territorial e o grande número de fieis, o trabalho Na capa e por dentro: uma análise sociohistórica sobre a mulher evangélica em publicações assembleianas ${ }^{5}$ analisou a representação feminina projetada por dois periódicos da editora CPAD (Casa Publicadora das Assembleias de Deus). A partir desse estudo, identificou-se nesse conjunto de revistas legitimadas pela instituição e em larga medida consumida pelas mulheres assembleianas, um aparato normatizador tanto para regulação das condutas femininas quanto para a construção de uma representação ideal de mulher.

As páginas subsequentes trazem como proposta discutir uma perspectiva de abordagem dessa representação de mulher assembleiana, conforme o que consideramos conceitos fundamentais para estudar as relações de gênero, de forma menos reduzida. A utilização de Judith Butler, Marilyn Strather e Talal Asad, nesse sentido, possibilitariam compreender a construção das categorias de sexo, gênero e corpo a partir de um viés histórico e culturalista. As ideias de tais autores auxiliam-nos para uma reflexão crítica acerca da representação da mulher evangélica assembleiana.

Esse artigo tem caráter ensaístico, ou seja, não intenciona ser um texto completo e finalizado. Ao contrário, pretende levantar questões reflexivas acerca de como o feminino pode ser analisado de forma mais frutífera no interior da Assembleia de Deus com base, sobretudo, em dois periódicos publicados pela CPAD.

Tendo em mente levantar apontamentos a partir de uma teoria de gênero pósestruturalista, mais articulada à contemporaneidade, torna-se imprescindivel abordar a perspectiva estruturalista, o movimento feminista e a necessidade de problematização de conceitos estanques. A pretensão é abordar tais temas de forma natural, e, espera-se, que um assunto se ligue ao outro, sobretudo, pela busca da questão central: de qual forma pode-se analisar a mulher evangélica assembleiana sem que ocorram reducionismos?

Para a finalidade desse artigo, as mulheres assembleianas trazidas para a presente discussão são referentes às fontes classificadas e analisadas a partir, sobretudo, dos periódicos publicados pela CPAD. Dessa forma, os relatos, matérias e apontamentos

\footnotetext{
${ }^{3}$ Ainda que esteja no singular, salienta-se que a denominação Assembleia de Deus não pode ser interpretada como uma igreja homogênea. Pelo contrário, a denominação é composta por inúmeros Ministérios, desde autônomos a filiados à CGADB (Convenção Geral das Assembleias de Deus no Brasil) e à CONAMAD (Convenção Nacional das Assembleias de Deus Madureira). No presente trabalho além das duas revistas dirigidas à mulher, publicada pela CGADB, ainda serão mencionadas duas igrejas Assembleia de Deus pertencentes ao Ministério Missões e ao Ministério Plantar.

${ }^{4}$ IBGE, Censo Demográfico. Disponivel em: $<$ http:/ / www.ibge.gov.br/estadosat / temas.php?sigla=ac8ttema=censodemog2010_relig $>$. Acesso em: 2 jul. 2015.

${ }^{5}$ NETO, Ana Luíza Gouvêa. Nacapa e por dentro: uma análise sócio histórica sobre a mulher evangélica em publicações assembleianas. 2015. 148f. Dissertação (Mestrado em Ciência da Religião) - Universidade Federal de Juiz de Fora, Juiz de Fora, 2015.
} 
adiante referem-se às matérias trazidas nas revistas Nosso Lar e Mulher, Lar \& Família Cristã, a uma entrevista com um pastor da Assembleia de Deus - Missões e, à observação participante durante o $2^{\circ}$ Congresso da UMAMP (União de mulheres em ação do Ministério Plantar).

\section{Perspectivas estruturalista e a consequente problematização da categoria mulher}

As revistas Nosso Lar e Mulher, Lar \& Família Cristã, somam um total de quarenta volumes, sendo treze volumes de Nosso Lar e vinte e sete de Mulher, Lar \& Família Cristã. Ao analisar o conjunto de textos, pode-se concluir que a representação de mulher e de feminino é balizada por uma noção construída com objetivo de controle e disciplinarização dos corpos femininos. Isso, em parte, por causa dos tipos de instruções e orientações que as revistas disponibilizam.

Percebe-se nas revistas certa tendência para um esquema binário de classificação da mulher e do feminino, segundo o qual, cabe-lhe somente a representação de submissa/passiva, se obediente ou altiva/ativa, se insubordinada.

Analisar as revistas a partir de um viés dicotômico parece insatisfatório na medida em que o retrato fornecido pela observação e análise dos periódicos aponta mais para uma representação de feminino que a instituição religiosa - Assembleia de Deus - pretende do que, possivelmente, na prática, as ações e relações sociais podem revelar.

Analisar as mulheres assembleianas trazidas nos periódicos à luz de uma perspectiva de gênero estruturalista pode ocasionar conclusões reducionistas, para as quais faltam-Ihes uma problematização mais refinada. Pode-se dizer que são identificados dois ideais femininos, concomitantes, nos periódicos. Ora a mulher é identificada no espaço doméstico, ora identificada no espaço público. Entretanto, a partir de uma análise superficial, o pesquisador pode atingir conclusões insatisfatórias, tal qual: que o tipo de mulher assembleiana trazido pelos periódicos é voltado para a domesticalidade, submissa a igreja e ao marido. A passagem a seguir deixa clara a identidade feminina cristã pautada no binarismo projetada pelos articulistas das revistas:

Nosso Lar acaba de nascer e começa a dar seus primeiros passos editoriais [...] a família cristã encontrará nas páginas de Nosso Lar o espaço adequado para sua edificação. Nosso Lar pretende vivenciar o dia a dia da família, respondendo às expectativas geradas pela vida moderna, que tanto pesam no comportamento do marido, como chefe de família, da esposa, como dona de casa e dos filhos como prolongamento social (NOSSO LAR, 1992, p. 1).

Já na primeira página do primeiro volume da revista Nosso Lar, em seu corpo editorial, escrito pela Redação, é possível perceber uma diferenciação entre os sexos/gêneros. Ao classificar o marido como chefe de família - aquele que provê a manutenção e estabilidade econômica da família - e a mulher como dona de casa - 
profissional do lar -, a revista marca sua postura em relação aos papéis os quais homens e mulheres devem ocupar na sociedade.

Concluir que a imagem feminina projetada pelas revistas é pautada na domesticalidade, na submissão à igreja e ao marido parece o caminho mais simples se consideramos um ponto de partida tomado para a análise, de maneira a-histórica e universalizante. Essa perspectiva deixa sem explicação situações como a matéria realizada com Marina Silva, à época Ministra do Meio Ambiente, leia-se trecho da reportagem:

\begin{abstract}
Simplicidade e serenidade são qualidades que saltam aos olhos quando se está a frente de Marina Silva. Reconhecida por sua luta e compromisso em favor das causas ambientais e dos direitos humanos [...] conquista posições de destaque na vida pública nacional sem deixar de lado a humildade e a gratidão a Deus [...] Marina surgiu no cenário público em 1988 ao ser eleita vereadora por Rio Branco, capital do Acre. Já no segundo mandato no Senado foi nomeada pelo presidente Luís Inácio Lula da Silva para fazer parte do primeiro escalão do governo (MULHER, LAR \& FAMÍLIA CRIST Ã, 2003, p. 5).
\end{abstract}

Como explicar a participação de uma mulher assembleiana na esfera pública, que de acordo com a visão estruturalista seria apenas lócus masculino? Tal pergunta coloca em cheque tanto o estruturalismo, quanto o discurso oficial da igreja projetado pelas revistas. Sales (2003, p.159-188) aponta para três tipos de críticas, sob as quais o estruturalismo deve ser pensado: uma crítica metodológica, uma crítica epistemológica e uma crítica de cunho filosófico. Interessa-nos, sobretudo, para o presente ensaio, o caráter secundário relegado à história no tocante à perspectiva estruturalista, no qual a história "ao invés de explicar, funciona como fator de perturbação - ela só aparece como vetor de alteração do sistema a ser compreendido e se efetiva pela comparação de diversos estados, anteriores e posteriores, do sistema" (2003, p. 171). Nesse sentido, há uma possibilidade de comparação de diversos modelos de sistemas na busca de uma estrutura que ordene e opere o funcionamento geral a partir das relações entre as partes que compõem o todo.

Interessa-nos, também, destacar o seguinte ponto: apesar de ser trabalhado de maneira que suscite complementaridade, como se sabe, a utilização de antônimos como base para estrutura sociocultural fundamenta todo o pensamento relacionado à corrente estruturalista. Sendo assim, a divisão sexual das coisas e das atividades assume uma postura binária, na qual sempre haverá a oposição entre o masculino e o feminino. Cima/embaixo, frente/atrás, duro/mole, seco/molhado são exemplos de antônimos utilizados para conferir conotações e correspondências aos gêneros. A tabela trazida abaixo sintetiza tal pensamento estrutural.

Tabela 1. Oposições binárias conforme o gênero ${ }^{6}$

\begin{tabular}{|c|c|}
\hline Masculino & Feminino \\
\hline Dominante,Cultura, Direito & Dominado, Natureza, Esquerda \\
\hline Seco & Úmido \\
\hline Aberto & Fechado \\
\hline
\end{tabular}

${ }^{6}$ BOURDIEU, 2011. p. 19.

Numen: revista de estudos e pesquisa da religião, Juiz de Fora, v. 18 n.2 


\begin{tabular}{|c|c|} 
Mente & Corpo \\
\hline Razão & Emoção \\
\hline Público & Privado \\
\hline
\end{tabular}

Criada a partir do livro $A$ dominação masculina, a tabela acima expressa a maneira pela qual os papeis de gênero são interpretados a partir de um viés estruturalista. Neste esquema, à mulher, biologicamente fêmea, cabe o espaço do privado, da emoção e, ao homem, biologicamente macho, cabe o espaço do público, da razão. Submetido ao masculino, tal qual natureza/cultura, mente/corpo, o feminino necessitaria da oposição ao masculino para ter significação ${ }^{7}$. E a distinção entre sexo/gênero ocorreria da mesma forma, ou seja, a partir de um feminino biológico, haveria que se construir um feminino (gênero) subordinado e em consonância com o sexo.

Acordar, fazer o café, arrumar a casa, preparar o almoço, arrumar as crianças, leva-las ao colégio, fazer compras, lavar a roupa, pegar as crianças no colégio, passar a roupa, preparar o jantar, lavar a louça, pôr as crianças para dormir [...]. Algumas donas de casa ficam tão envolvidas com seus afazeres domésticos, e os maridos tão envolvidos com os problemas do trabalho, que se esquecem de um momento muito importante: seu momento a sós com Deus (NOSSO LAR, 1995 , p. 26-27).

O trecho acima faz parte da matéria intitulada, que espaço Deus ocupa em sua vida? escrita por Adilson Faria Soares, à época pastor presidente da Assembleia de Deus Mutuá, no Rio de Janeiro. Nota-se que tanto a Redação quanto o autor convidado tratam com a mesma perspectiva os papéis ocupados por homens e mulheres na sociedade, construída a partir da diferenciação biológica entre os sexos.

Assim, tem-se que o sexo é fundamentado a partir da biologia e o gênero tem sua fundamentação a partir da construção social/cultural. Seguindo esse pensamento, sexo, gênero e orientação sexual são interpretados de maneiras correlacionadas e dependentes. Logo, aquela mulher assembleiana que é juíza em um tribunal no estado do Pará ${ }^{8}$ não estaria em conformidade com os atributos referentes ao seu gênero.

Não bastasse o recorrente uso e abuso de antagonismos, o viés estruturalista propõe uma essência universal para o modelo androcêntrico e patriarcal de sociedade. Aqui, aponta-se para duas observações intercambiáveis: 1. A necessidade de problematizar a categoria universal; 2. A necessidade do movimento feminista em tornar coesa a identidade mulher.

Ao trabalhar o conceito de religião $\mathrm{Asad}^{9}$ aponta para uma reflexão que pode ser aplicada à teoria de gênero. Embora o conceito trabalhado pelo autor seja distinto, tomaremos por empréstimo os argumentos chave que elaborou. Assim, propomos que para trabalhar seja a dominação masculina, seja o androcentrismo, ou mesmo as categorias

\footnotetext{
${ }^{7}$ BUTLER, 2015. p. 65-67.

${ }^{8}$ MULHER, LAR \& FAMÍLIA CRISTÃ. 2001, p. 52.

${ }_{9}$ ASAD, 2015, p. 263-284.
} 
de sexo e gênero, é necessário pensar em contextos e historicidades. A construção de conceitos, discursos e sistemas reguladores obedecem a pré-condições que geram efeitos socialmente identificáveis em seus próprios contextos.

Como se vê, o argumento básico aqui gira em torno da impossibilidade de haver uma definição universal de certas categorias ou sistemas, pelo fato de que os elementos que os constituiriam e as relações que dele se resultariam seriam específicos historicamente de seus contextos. Como também, a construção das definições seria, em si, produto de processos discursivos históricos.

Em síntese, o autor nega a generalização dos $\operatorname{conceitos}^{10}$, sobretudo de religião, ao defender que tal se caracteriza como um ato. A concepção universal de religião pode ser vista como errônea a partir do momento em que se torna necessário levar em consideração o desenvolvimento da definição de religião como um ato histórico. Pensar a historicidade da própria construção do conceito implica pensar em diferentes variáveis, tais como: pensamentos, épocas, contextos geográficos. E, que a construção de definição responde às questões específicas de cada variável.

Vê-se o mesmo raciocínio em Butler", ao defender gênero como ato, aberto a ações. Ora, tais insights têm uma ideia chave: que toda definição de elemento ocorre dentro de um contexto histórico particular. $\mathrm{E}$, que tais definições estão constantemente sendo definidas dentro de contextos históricos e sociais, nos quais quem os define tem motivos e razões para definir de um modo ou de outro.

Mônica, capitã do exército, branca, formada em Direito e em Teologia, 30 anos $^{12}$, Judite, dona de casa, esposa de um pastor, negra, 47 anos $^{13}$, Débora, aluna do curso de Letras, branca $^{14}$. É suposto que tais mulheres, com carreiras, idades e raças tão distintas tenham uma mesma identidade?

A resposta para a pergunta acima é SIM, para parte do movimento feminista. Tal parcela do movimento, diga-se de passagem, radical, interessa-se na promoção dos interesses das mulheres. Mas desde quando lutar pelos interesses das mulheres é visto como algo pejorativo e radical? Strathern ${ }^{15}$ aborda o movimento feminista como produtor de um debate radical acerca dos interesses femininos. Levando em consideração a data em que o livro foi escrito, década de 1980, tal afirmação que o debate feminista é radical soa descontextualizada. Contudo, é seguro afirmar que ainda hoje, encontra-se certo radicalismo em movimentos feministas, tais como: o FEMEN ${ }^{16}$, grupo feminista de

\footnotetext{
10 ASAD, 2015.

"BUTLER, 2012. p. 199.

${ }^{12}$ MULHER, LAR \& FAMÍLIA CRISTÃ, 2003, p, 50.

${ }_{13}$ MULHER, LAR \& FAMÍLIA CRISTÃ, 2005, p. 5.

${ }^{14}$ MULHER, LAR \& FAMÍLIA CRISTÃ, 2003 p. 50.

${ }^{15}$ STRATHERN, 2006. p. 53.

${ }^{16}$ Em um protesto intitulado Topless Jihad, corrido em 2013, as ativistas conseguiram não somente apoio, mas também crítica por parte de muçulmanas. "A natureza intransigente das ações do Femen e as palavras provocadoras que portam em cartazes e no corpo, também irritam outras pessoas. Após o Topless Jihad, formou-se um grupo denominado Muslim Women Against Femen (Muçulmanas contra o Femen), que declarou no Facebook considerar o Femen anti-islâmico e imperialista (Disponível em: < http:/ / www.dw.com/pt / a\%C3\%A7\%C3\%B5es-do-grupo-femen-provocam-recha\%C3\%A7o-de-feministas/a-
}

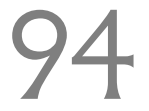


protesto, cujas ações no centro da cena pública protagonizam atos pela liberdade de mulheres que as manifestantes feministas julgam ser oprimidas, seja pelo machismo, seja pela desigualdade entre homens e mulheres na sociedade, seja pelas religiões e suas estruturas androcêntricas.

No cerne do debate radical, a perspectiva das mulheres é tida como forma de resistência e/ou em conflito com a dos homens em um sistema, no qual a posição da mulher é vista como consequência dos interesses masculinos. Tal suposição se torna ainda mais problemática ao interpretar a desigualdade entre os sexos como um fenômeno universal. Se no interior do movimento existem diferenças teóricas, como se pode falar em feminismo unitário ou mesmo na unidade da categoria mulher?

Em princípio, o termo mulher foi responsável por tornar coeso o movimento feminista na luta por projeção, legitimidade e direitos políticos. Ao buscar chancelar o sujeito mulher na esfera pública, o feminismo optou e, por assim dizer, necessitou da criação de uma identidade única a qual representasse de forma igualitária os interesses do movimento feminista. Contudo, boa parte do movimento não acompanhou o desenvolvimento do mesmo, principalmente, no que diz respeito à autorreflexão. Seria necessário e aceitável pensar a categoria mulher em termos universais nos dias de hoje? A seguir, leia-se o editorial de Nosso Lar, número quatro:

Não bastasse as inovações, esta edição tem um aspecto todo especial. Nossa homenagem a você esposa, dona de casa, trabalhadora [...]enfim, a você mulher [...] que tem nos prestigiado a cada edição e, com fervorosas orações, ajudado o nosso jornadear. Maria, Fátima, Ana ou Tereza [...] não importa o seu nome, idade, cor ou classe social. $O$ que importa é que, como mulher, você exerce um papel importante no mundo, na igreja, na família, na obra de Deus (NOSSO LAR, 1995, p. 1).

Assim como boa parte do movimento feminista não acompanhou 0 desenvolvimento do termo mulher, ao analisarmos o trecho acima, torna-se evidente que também o discurso oficial da Assembleia de Deus (ligada à CGAD) não foi alterado. De acordo com Bandini (2009) a mística feminina é reforçada não somente através dos homens, mas também, através de algumas lideranças femininas. Que por consequência "desvaloriza as mulheres para outras funções que não estejam ligadas à família e a unidade doméstica" (BANDINI, 2009, p. 5). O discurso oficial da Assembleia de Deus, em mais de 100 anos de história, pouco foi alterado no que diz respeito à relação entre mulher colocamos no singular para marcar a identidade única projetada pela igreja - e seu papel de adjutora, mãe e dona de casa. A ela ainda é negada a ordenação ao pastorado, tema abordado na primeira Convenção Geral da Assembleia de Deus.

As irmãs têm todo o direito de participar na obra evangélica, testificando de Jesus e a sua salvação, e também ensinando quando for necessário. Mas não se considera justo que uma irmã tenha a função de pastor de uma igreja ou de

16741110 >. Acesso em: 6 nov. 2015". Frases como: "Femen pratica o feminismo brutal (Hilal Sezgin)" não são incomuns após os protestos do grupo. 
ensinadora, salvo em casos excepcionais mencionados em Mateus [...] Isso deve acontecer somente quando não existirem na igreja irmãos capacitados para pastorear ou ensinar (ARAÚJO, 2007, p. 211).

As Convenções Gerais de 1983 e de 2001 voltaram a abordar o ministério feminino dentro da igreja. Tal pauta foi rejeitada por unanimidade e, por grande maioria, respectivamente. A máxima assembleiana ainda nos parece ser "E Disse o senhor Deus: Não é bom que o homem esteja só far-lhe-ei uma adjutora" (Gn 2:18). O ideal de mulher assembleiano tem por base a mulher como adjutora, quer seja no âmbito familiar, quer seja no mercado de trabalho. Tal concepção de identidade com base fixa feminina pode ser comprovada através da análise das revistas, como também da entrevista realizada com um pastor da Assembleia de Deus - Missões, da cidade de Juiz de fora.

Em meio à crise de paradigmas universalistas e da crítica aos construtos de verdades absolutas, fez-se necessário problematizar tanto os conceitos bem delimitados, quanto as concepções vigentes, que têm por base características fixas e estanques, o que significa compreender que utilizar mulher com as implicações feministas radicais supõe uma identidade pré-estabelecida e com bases fixas.

\begin{abstract}
A presunção política de ter que haver uma base universal para o feminismo, a ser encontrada em uma identidade supostamente existente em diferentes culturas, acompanha frequentemente a ideia de que a opressão das mulheres possui uma forma singular, discernível na estrutura universal ou hegemônica da dominação patriarcal masculina (BUTLER, 2012, p. 20).
\end{abstract}

Tal concepção vai ao encontro da padronização da identidade mulher forjada pelos articulistas das revistas analisadas. Nota-se que apesar da diversidade de identidades femininas contidas nas páginas das revistas, há um esforço para relacionar a mulher ao espaço doméstico e à concepção de adjutora. Características que supõem-se relacionar ao feminino, constantemente são abordadas, tais como: a maternidade, a doçura, a delicadeza, a paciência, o cuidado estético.

Por que transformar identidades fluidas em identidades fixas e naturais? Quais os propósitos dessa normatização? Quem são os responsáveis por engendrar a naturalização de identidades únicas, universais e a-históricas? Tais perguntas tornam-se necessárias, a partir do ponto no qual pretende-se vislumbrar a construção da categoria de gênero, quais as relações contidas nessa categoria e qual o papel desempenhado pelas instituições detentoras de capital simbólico.

As instituições enquanto agenciadoras relacionam-se com a normatividade, com a organização, com o reconhecimento, com a aceitabilidade e com a legitimidade na conceituação de categorias de gênero? A igreja, enquanto tal tem responsabilidade na ordenação e normatização dos sujeitos, enquanto produtora de uma matriz de inteligibilidade? Mulheres que rompem com suas igrejas por falta de legitimidade, mesmo que empoderadas pelo Espírito Santo estariam rompendo com certa normatividade? Tais reflexões podem ser feitas a partir da problematização das categorias de gênero, corpo, normatividade.

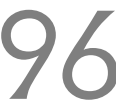

Numen: revista de estudos e pesquisa da religião, Juiz de Fora, v. 18 n.2 


\section{Gênero, corpo e normatividade à luz de Judith Butler}

Como compreender a mulher assembleiana a partir de uma perspectiva de gênero que dê conta de explicar as continuidades e descontinuidades entre a literatura produzida pela instituição religiosa e a autorrepresentação de feminino que possuem as assembleianas?

Ao longo do processo de análise documental das revistas Nosso Lar e Mulher, Lar \& Família Cristã é notável a recorrência com que mulheres aparecem de alguma forma inseridas no espaço público. São mulheres anônimas, mulheres públicas, mulheres negras, mulheres brancas, mulheres casadas, mulheres solteiras, mulheres jovens, mulheres idosas.

A identificação dessas mulheres atuantes no trabalho social, na educação, na política e em missões em outros países nos conduz a afirmar que tais agentes não poderiam ser classificadas como apenas submissas aos maridos, tal como verificamos no discurso oficial religioso. Muitas delas não são casadas e outras, mesmo quando casadas, decidiram abrir mão de uma vida centrada no doméstico a favor de uma vida pública. Nota-se que essas mulheres fazem política ao passo que precisam construir parcerias e relações para obtenção do resultado pretendido.

As mulheres retratadas anteriormente - atuantes na esfera política - saíram da esfera doméstica e ganharam o espaço público, visto como lócus masculino, de acordo com uma visão de gênero pautada no estruturalismo e perceptível nas páginas dos periódicos analisados. Torna-se necessário repensar o papel dessas mulheres tanto no espaço doméstico, quanto no espaço público. E, acredita-se que o princípio para tal reflexão seja a problematização da categoria gênero.

No tópico tratado anteriormente, há uma pista sobre como refletir acerca da categoria de gênero à luz do que há de contínuo e descontínuo entre o que propõe a literatura assembleiana, os perfis que divulga e torna público como exemplares e o que dizem a respeito de si as mulheres assembleianas. Tal qual a categoria religião e mulher enquanto identidade única, a categoria de gênero também deve ser abordada a partir do contexto histórico, no qual está inserido. É necessário refletir e repensar a noção estável sobre gênero.

O gênero é uma complexidade cuja totalidade é permanentemente protelada, jamais plenamente exibida em qualquer conjuntura considerada. Uma coalizão aberta, portanto, afirmaria identidade alternativamente instituídas e abandonadas, segundo as propostas em curso; tratar-se-á de uma assembleia que permita múltiplas convergências e divergências, sem obediência a um telos normativo e definidor (BUTLER, 2012. p. 37.).

A citação acima implica pensar a noção de gênero a partir de um viés culturalista e histórico, de maneira próxima ao que compreendeu Strathern (2010) ao estudar a sociedade Hagen. Para a autora, não se pode fixar identidade em corpos, muito menos uma essência. A constituição de identidades se dá a partir das relações sociais, dessa 
forma, ora os Hagen assumem características femininas, ora características masculinas. Ao fazer uma etnografia em uma sociedade na qual a troca estabelece relações sociais e pauta a organização da comunidade, Strathern observa que "é a posição ativa que é tomada como a posição masculina. Os homens que recebem a riqueza estão em uma posição receptiva, portanto, feminina" (2010, p. 7). A primeira publicação do corpo editorial de Mulher, Lar \& Família Cristã talvez seja um bom exemplo da necessidade de pensarmos gênero, enquanto categoria analítica dotada de historicidade e relações socioculturais.

\begin{abstract}
Estamos aqui diante de um novo e agradável desafio. Produzir uma revista direcionada à mulher cristã. Ativa no campo profissional, político e no lar, a mulher que serve a Deus concilia tudo isso com uma participação dinâmica nas atividades da igreja, precisa estar consciente dos propósitos divinos para a sua vida e bem preparada para os desafios diários [.... A difícil tarefa de conciliar trabalho e carreira profissional é o tema abordado na reportagem de capa. A tarefa da mãe moderna não mais se resume a cuidar da organização da casa. Além de se dedicar aos filhos, ela também se preocupa com a carreira profissional (MULHER, LAR \& FAMÍLIA CRISTÃ, 2000, p. 4).
\end{abstract}

É possível notar uma postura mais flexível em relação à imagem feminina. Neste primeiro editorial, percebe-se a preocupação da revista em mostrar uma mulher atuante no espaço público. A Assembleia de Deus de ethos sueco nordestina, sectária, apolítica e de visões pré-milenaristas, na atualidade, tem características bem distintas. A passagem de Mulher, Lar \& Família Cristã demonstra a adaptação da igreja ao contexto histórico no qual está inserida, o que traz consequências, ainda que não consciente da fluidez da categoria gênero. Tais consequências abrem espaço para desconstrução, reelaboração, resistência, subversão, etc. da perspectiva de identidade feminina pré-formatada e estanque. Em seu livro, Bandini (2014) demonstra que mesmo as instituições mais conservadoras, tal como a Assembleia de Deus, têm se indagado sobre as transformações para além do espaço religioso tendo em mente que seus seguidores pertencem a uma sociedade histórica e sociocultural, na qual recebem informações e condutas de vida diferenciadas da orientação oficial contida no discurso religioso. E que as mulheres encontram na falsa submissão, na resistência velada formas de subversão da matriz de inteligibilidade religiosa, consequentemente, galgando novos espaços e novas formas de poder no interior do espaço religioso.

Nesse sentido, a noção de gênero como algo performativo feita por Butler (2012, p. 48) parece se encaixar. Pensar em gênero enquanto performance é pensar em algo em constante construção, e que ganha significado no interior do discurso. Ou seja, não há como afirmar que exista uma identidade de gênero atrás das representações de gênero; mas sim, uma identidade constituída de forma performativa, por expressões que supostamente são seus resultados. $\bigcirc$ gênero tido enquanto ato, é aberto a múltiplas ações, intencional, performativo e ritualizado através de constantes repetições ao longo do espaço/tempo. $\bigcirc$ gênero pode ser interpretado enquanto ato, a partir do ponto em que necessita de constantes repetições para sua constituição. Dessa maneira, a construção de uma identidade única cai por terra, uma vez que o gênero não é fixo, até mesmo para a 
visão estruturalista. As revistas podem indicar a domesticalidade e a submissão como atributos femininos, ainda, presentes em mulheres notoriamente bem sucedidas nos espaços públicos, mas a performance de tais mulheres parece alça-las a um patamar menos circunscrito pela norma religiosa, entrementes, veiculada na linha editorial dos magazines evangélicos. Isso, portanto, parece conotar uma categoria de gênero mais fluida.

Mãe e profissional: como conciliar? Mostra as dificuldades que as mães encontram para manter suas carreiras, sem que isso prejudique sua relação com os filhos [...] Mesmo trabalhando fora, mulheres investem na estruturação da família [...] Primeiro lugar está em Deus, segundo, a família e depois, a profissão (MULHER, 2000 p. 7).

A partir do ponto em que a categoria gênero não é fixa, abrem-se possibilidades para múltiplas interpretações do próprio sexo, considerado base fundante para a construção do gênero. E parece que as mulheres estão fazendo isso, quer seja de forma inconsciente ou através de subversão velada essas mulheres estão encontrando formas de reinterpretar seus próprios gêneros tornando-se agentes históricas e não meras espectadoras. Tamanha é a transformação que a própria igreja se vê na obrigação de alterar o discurso oficial a fim de permanecer em sintonia com seus fiéis. Ora, se a constituição do gênero não é fixa, mas móvel e historicizada, não parece haver sentido em quantificar tanto a categoria de gênero, quanto a de sexo. E Butler (2012) vai além, propõe que a própria categoria de sexo seja um construto social e que talvez, sexo e gênero sejam as mesmas coisas.

Strathern (2006) ao analisar a sociedade na Melanésia traz exemplos da constante necessidade de historicizar e contextualizar o objeto de estudo. De acordo com a autora, as categorias de gênero e sexo são constituídas a partir das relações sociais. Correndo o risco de soar estruturalista, vale a pena destacar o wok meri, que chama atenção ao colocar as mulheres em posição ativa, ou seja, inseridas no espaço público e com pretensões masculinistas de gênero.

\footnotetext{
Em parte como resposta ao controle dos homens sobre o dinheiro no nível familiar, as mulheres dessa região desenvolveram suas próprias poupanças e um sistema de crédito, com características adotadas deliberadamente de acordo com o que conhecem sobre procedimentos bancários [...] Grupos construídos por esposas de linhagens co-residentes de uma aldeia protegem suas economias de pilhagem de seus maridos organizando coletivamente uma atividade bancária e usando o capital para empreendimentos de risco e para empréstimos a grupos similares de mulheres [...] Um homem pode atuar também como porta-voz do grupo nas ocasiões públicas. $\bigcirc$ foco de tais ocasiões, contudo, são as transações das mulheres, e o dinheiro é dado e recebido em nome delas (STRATHERN, 2006, p. 139).
}

A autora defende que, nesse ponto, importa compreender que as mulheres ao estarem em posição ativa, assumem uma postura de gênero tida como masculina. Talvez, não devessem ser entendidas como masculinas, mas apenas como outra maneira de acionar o gênero, enquanto categoria não fixa. A reportagem subsequente evidência as múltiplas 
maneiras de interpretar e acionar o gênero, na qual a mulher é exaltada justamente pelo seu lado profissional.

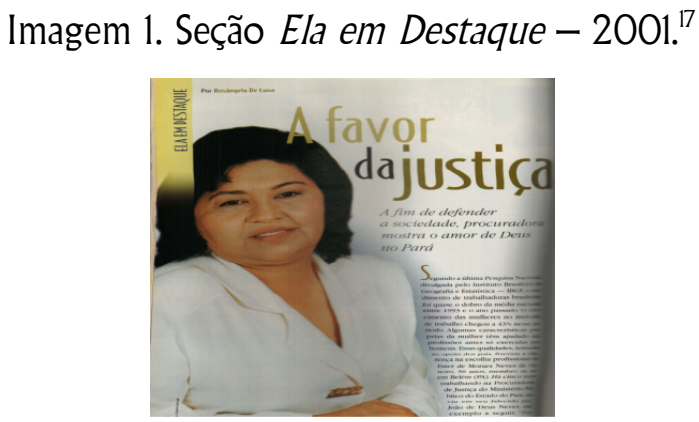

Nesse sentido, aquelas mulheres assembleianas citadas anteriormente que ultrapassam o espaço do doméstico, agora, podem ser pensadas de forma distinta. Pensar na mulher enquanto categoria analítica supõe pensar em relações sociais, culturais e políticas em que esta está inserida. E que a interpretação de seu gênero, constantemente construída, arranjada, formulada e reformulada, age de acordo com os contextos.

\section{A produção de gênero nas revistas assembleianas}

Ao quantificar as categorias de sexo e de gênero, se exclui uma gama de possibilidades de interseções sociais, culturais e políticas. A contextualização e historicização da categoria é constantemente negada por sujeitos que defendem tanto a quantificação do gênero, quanto do sexo. Pensar em construção de conceitos, categorias, significa pensar em contextos históricos em que esses estão inseridos. Consequentemente, há que se considerar os agenciamentos de poder que regularizam e organizam a matriz de legitimidade que tornam as manifestações de gênero aceitáveis ou não.

Se sexo e gênero são construtos sociais, de qual forma tais categorias são construídas de maneira a parecerem fixas, universais e compostas por binários? A compreensão do gênero enquanto ato (performativo e ritualizado através de práticas), consequentemente, requer uma identidade como uma prática significante. $\mathrm{E}$, isso quer dizer, que os sujeitos culturalmente inteligíveis são resultado de um discurso composto por regras e normas forjadas no interior de uma matriz de inteligibilidade. No que diz respeito às revistas, o discurso projetado nelas representa o discurso oficial da igreja no qual a matriz de inteligibilidade é passada para o público. Infelizmente, no total de vinte e sete articulistas, apenas cinco são mulheres na revista Nosso Lar, o que representa cerca de $18,52 \%$ de mulheres produzindo matérias para outras mulheres. Ao olharmos os

${ }^{17}$ MULHER, LAR \& FAMÍLIA CRISTÃ , 2001, p. 52. 
articulistas de Mulher Lar \& Família Cristã verificamos que a percentagem de articulistas mulheres salta de $18,52 \%$ para $33,33 \%$, o que representa um avanço para a equidade de gênero. Ainda que a disparidade entre homens e mulheres tenha diminuído o discurso oficial, responsável por propagar e produzir a matriz de inteligibilidade permanece sendo produzido através da visão masculina.

Pode-se entender, enquanto matriz de inteligibilidade, o campo em que políticas estão em jogo. Forjado a partir das agências detentoras de capital simbólico, este é responsável pelas formas as quais os gêneros são construídos, se tornam inteligíveis e, consequentemente, são legitimados. Nesse sentido, é a ordem cultural quem dita as normas para a inteligibilidade dos sexos e gêneros.

Tais normas operam inseridas nas práticas sociais e quando têm por finalidade a normatização, operam de maneiras implícitas. Apesar da dificuldade de leitura e discernimento de tais, podem ser vislumbradas nos efeitos que produzem ${ }^{18}$. A norma governa a inteligibilidade e discerne sobre a possibilidade de certos tipos de práticas e ações reconhecíveis. Dessa maneira, como reconhecer a normatização das mulheres assembleianas dentro da igreja e nas revistas analisadas?

\begin{abstract}
Elas se organizam no serviço social e em grupos de oração, de visitas, de louvor, de apoio específico à família nos núcleos familiares, realizando cultos edificantes [...] a submissão foi dada à mulher pelo Senhor, como um princípio que não pode ser ignorado. Primeiramente ao Senhor, e depois ao homem, a quem Deus constituiu como "cabeça" da mulher [...] ser feminina é diferente de ser feminista (MULHER, LAR \& FAMÍLIA CRIST $\tilde{A}$, 2003, p. 35).
\end{abstract}

A passagem evidencia a normatização ideal proposta pela igreja, na qual homem e mulher são vistos como duas variantes, superior e inferior. De acordo com a revista, não se deve questionar a submissão da mulher, uma vez que o homem é a parte racional do casal. A liderança feminina, nesse ponto, está ligada a um homem - ser pensante, racional - para direcionar a mulher - dotada de sentimentalismo e emoções - à liderança. As linhas sugerem um princípio de divisão entre masculino - ativo - e feminino - passivo e, por conseguinte, uma hierarquia fundamentada na divisão de gênero.

O gênero serve de aparato para a produção e normatização das identidades masculinas e femininas. E o que se pode perceber a partir da análise dos periódicos é um discurso restritivo sobre os gêneros e sobre os papeis sociais desempenhados por cada um. Nota-se um discurso amarrado à vertente estruturalista que reduz gênero e sexo ao binarismo. Isso acaba por reforçar uma operação regulatória de poder que legitima e naturaliza formas hegemônicas e excludentes de compreender o sexo e gênero e solapa possibilidades de se pensar para além do binário.

[...] podríamos decir que el campo de realidad producido por lãs normas de gênero constituye el telón de fondo para la aparición em la superfície del gênero em sus dinensiones idealizadas (BUTLER, 2005, p. 23).

${ }^{18}$ Cf. BUTLER, 2005, p. 10. 
Nesse sentido, pode-se dizer que as pessoas são reguladas pelos gêneros, nos quais as normas estão operando, e que a partir dessa regulação as pessoas são reconhecidas, culturalmente, de formas inteligíveis e aceitáveis, ou, não. Mas como compreender sujeitos que não se enquadram dentro das normas? Tais pessoas podem ser interpretadas como sujeitos? $E$ as mulheres assembleianas que não se adequam as normas, sofrem consequências?

Pensar em sujeito requer pensar em pessoas que têm reconhecimento perante a lei e perante a vida política. $\bigcirc$ que significa dizer que existem termos de reconhecimento condicionando quem será considerado como sujeito. E que tais termos são pautados pelas normas incididas sobre as relações de gênero e sobre a constituição de identidades. Contudo, é seguro afirmar a existência de corpos que não se enquadram às normas e aos códigos de inteligibilidade vigentes. Para Butler (2002, p. 155-167) tais corpos podem ser considerados como abjetos, ao passo da inaceitabilidade destes, por regras de inteligibilidade. Embora tais corpos não possuam legitimidade, eles têm significados e são materializados. Por corpos abjetos entende-se:

A todo tipo de corpos cujas vidas não são importante. Não é o que é impensável, que aquilo que não pode ser vivido ou compreendido não tenha uma vida discursiva; ele certamente a tem. Mas ele vive dentro do discurso como figura absolutamente não questionada, a figura indistinta e sem conteúdo de algo que ainda não se tornou real (BUTLER, 2002, p. 161-162).

A abjeção dos corpos ocorre dentro de um processo discursivo no contexto social. Em que operam relações sociais e poderes com possibilidades de construir significados de acordo com seus interesses. Os corpos, compostos por fronteiras fluidas e por discursos, são capazes de materializar identidades e manifestações de gênero. Ocorre que nem sempre a identidade materializada é aceitável na matriz de inteligibilidade. Podemos utilizar como exemplo o $1^{\circ}$ Congresso Nacional da UFADEB (União Feminina da Assembleia de Deus de Brasília), realizado em Belo Horizonte. $\bigcirc$ qual teve por objetivo mostrar o aumento da participação feminina dentro da igreja e a importância da mulher para construção e manutenção da instituição. Em um Congresso feminino é de se esperar que a mulher tenha papel preponderante, caso que não ocorre no que diz respeito à organização do evento. $O$ evento para comemorar a participação feminina na Assembleia de Deus não só foi organizado, mas também presidido, por um homem. Como explicar essa discrepância entre objetivo e prática? E é disso que se trata a abjeção, a sinalização de comportamentos e identidades que estão fora do esquema binário (no caso, a capacidade de mulheres organizarem e presidirem seus próprios eventos) em que os sexos/gêneros estão inseridos. Tal prática também pode ser verificada no livro de Bandini ${ }^{19}$. Os discursos e práticas reforçam uma normatização de ideal feminino e, tal reforço à materialização de identidades e manifestações de gênero pode ser observado em uma das seções de Nosso Lar.

${ }^{19}$ BANDINI, 2014. p. 244. 
A seção Passo a Passo está presente em dez edições de Nosso Lar. O Passo a Passo da primeira edição traz em suas páginas moldes e as formas para se confeccionar um Blazer. A coluna dirige-se exclusivamente às mulheres, e a passagem a seguir corrobora essa afirmação.

É muito gratificante quando fazemos algo, com nossas próprias mãos, que se torna objeto de admiração e elogio. Na seção Passo a passo, apresentaremos ideias práticas e fáceis que você mesma poderá desenvolver. Nesta edição, ensinaremos como confeccionar uma peça versátil e que nunca sai de moda: o blazer. Pegue agulha, linha, tesoura [...] e mãos à obra! (NOSSO LAR, 1992, p. 10).

O trecho acima evidencia o direcionamento da coluna. Ao utilizar o pronome de reforço no feminino - mesma - , a revista explicita quem é seu interlocutor. Verifica-se que há uma construção de gênero relacionada a uma identidade, e, nesse contexto, a estrutura binária de gêneros naturaliza a divisão do trabalho. Assim, quando o texto propõe ao leitor que pegue agulha, linha e tesoura, ainda que o pronome de reforço não estivesse no feminino, a proposta seria feita às mulheres, inseridas em um ambiente doméstico e às voltas com os afazeres diários de dona de casa.

A coluna reforça a ideia de divisão do trabalho e de hierarquia sexual, ao supor que costura seja trabalho feminino. Não obstante, marca como os corpos aceitáveis devem se comportar, de acordo com suas identidades generificadas, no que diz respeito às indumentárias, bem como de qual maneira devem vivenciar seus gêneros de acordo com uma matriz de inteligibilidade que baliza as funções de cada sexo/gênero. As linhas a seguir trazem um exemplo de tensão a partir dos corpos, a qual não podemos identificar nas páginas das revistas, já que as mulheres projetadas agem de acordo com seus sexos/gêneros no interior da matriz de inteligibilidade.

Em entrevista com um pastor ${ }^{20}$, o qual terá seu nome abordado de forma fictícia para preservação da identidade, de uma das Assembleias de Deus da cidade de Juiz de Fora - MG, foi relatado que há um tempo o mesmo havia acolhido uma fiel que estava procurando ajuda. A fiel, ex-membro de uma Assembleia de Deus, havia sido expulsa por ter ficado grávida, enquanto jovem e solteira. Esse relato demonstra o poder de normatização dentro da igreja e a abjeção do corpo feminino. Não por se tratar de uma mulher, mas porque esta mulher não agiu de acordo com a matriz de inteligibilidade normatizada pela igreja: sua vida deixou de ter significado para os membros daquela determinada igreja. A identidade de mulher-jovem-solteria e grávida não materializava mais os padrões estabelecidos dentro do esquema binário certo/errado da comunidade, colocando-a numa posição frágil e precária.

Em corpos abjetos a violência pode se dar de maneira simbólica ou material, e quando isso ocorre constata-se a noção de precariedade tratada por Butler [2015, p. 321-

\footnotetext{
${ }^{20}$ Entrevista concedida por Carlos, Juiz de Fora, 23 nov. 2014.
} 
336). A precariedade está diretamente relacionada com as normas de gênero, pois os que não manifestam sua identidade de gênero de forma inteligível descobrem formas de acaso e violência, tal como o relato citado acima.

A performatividade do gênero influencia de forma direta como tal será vivenciado no espaço público através de atos de discurso e de reprodução de normas e regras. Tais vidas - abjetas e precárias - são caracterizadas como vidas não legíveis, ilegítimas e não dignas de reconhecimento. Percebe-se a partir de toda discussão a importância de se refletir de maneira crítica acerca da categoria de gênero.

\section{Considerações finais}

Buscou-se à luz de Judith Butler, Marilyn Strathern e Talal Asad problematizar algumas categorias consideradas como fixas e universais na perspectiva de gênero com viés estruturalista. Mostrou-se a problemática de encarar sexo e gênero como categorias universais a partir das formas binárias, como também o perigo de construir o conceito de identidade como algo fixo. Com essa discussão, que pretendeu esmiuçar os rendimentos do desconstrucionismo para a abordagem de casos específicos como o das mulheres assembleianas retratadas em revistas da instituição, procuramos demonstrar como mesmo os discursos oficiais podem deixar no texto subscrito pistas para a intermitência da categoria gênero e as representações de mulher e de feminino.

Isso posto, parece-nos que as reflexões trabalhadas acima abrem possibilidades para a compreensão da mulher evangélica assembleiana sem enquadrá-las em definições estanques. Percebe-se a necessidade de contextualizar e historicizar qualquer objeto de estudo. Dessa forma, compreender a igreja Assembleia de Deus dentro de um contexto geral é importante, contudo, há que se pensar nas relações e normatizações produzidas no interior da igreja. Vale ainda perguntar se o que a normatização documentada nessas revistas destinadas ao público feminino corresponde ao real ou ao que se pretende como real para essas mulheres?

Sob essa suspeita, a possibilidade de significações e ressignificações dos ideais normativos circulados no meio religioso, agora toma nova forma de compreensão. Ao passo que gênero e identidade são constituídos constantemente é possível interpretar os papeis de acordo com o contexto. Isso significa dizer, que a mulher assembleiana que trabalha fora está agindo conforme o seu gênero, seja ele qual for. Resta-nos persegui-lo em seus diferentes contextos, não para delimitá-lo em novos conceitos oclusivos, mas para compreender o significado das ações de quem o vivencia.

\section{Referências bibliográficas}

ARAUJO, Isael de. Dicionário do movimento pentecostal. 1. ed. Rio de Janeiro: CPAD, 2007.

ASAD, Talal. A construção da religião como uma categoria antropológica. Cadernos de Campo, n. 19, p. 263-284.

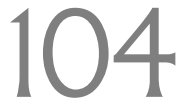


ASAD, Talal. Thinking about religious, belief, and politics. Disponível em: < file:/ / / C: / Users / Ana\%20Lu\%C3\%ADza/ Downloads/asadreligionpolitics.pdf>. Acesso em: 13 abr. 2015.

BANDINI, Claudirene Ap. P. Costurando certo por linhas tortas: práticas femininas em igrejas pentecostais. Salvador: Editora Pontocom, 2014.

. Transformações das identidades femininas no campo religioso pentecostal. Revista Brasileira de História das Religiões. v. 1, n. 3, 2009.

BÍBLIA SAGRADA. São Paulo: Editora Paulinas, 2009.

BOURDIEU, Pierre. A dominação masculina. Rio de Janeiro: Bertrand Brasil, 2011.

BUTLER, Judith. Como os corpos se tornam matéria. ESTUDOS FEMINISTAS, ano 10, p. 155-167, 2002.

Fundamentos contigentes: o feminismo e a questão do pós-modernismo.

Cadernos PAGU, n. 11, p. 11-42, 1998.

gênero é uma instituição mutável e histórica. Disponível em: < http:/ / www.ihuonline.unisinos.br/index.php?option=com_content\&view=article\&id=470 \&secao=199 >. Acesso em: 19 jun. 2015.

. Performatividad, precariedade y políticas sexuales. Revista de Antropologia Iberoamericana, v. 3, n. 4, p. 321-336, 2015.

- Problemas de gênero: feminismo e subversão da identidade. Rio de Janeiro: Civilização brasileira, 2012.

. Regulaciones de gênero. LAVENTANA, n. 23, p. 7-35, 2005.

DW, made for minds. Disponível em: < http: / / www.dw.com/pt/a\%C3\%A7\%C3\%B5esdo-grupo-femen-provocam-recha\%C3\%A7o-de-feministas/a-16741110>. Acesso em: 6 nov. 2015.

FEMENÍAS, Maria Luísa. Pós-feminismo através de Judith Butler. Estudos Feministas, v. 14, n. 2, p. 549-571, 2006.

GIUMBELLI, Emerson. A noção de crença e suas implicações para a modernidade: um diálogo imaginado entre Bruno Latour e Talal Asad. Horizontes Antropológicos, ano 17, n. 35, p. 327-356, 2011.

IBGE, Censo Demográfico. Disponivel em: < http: / / www.ibge.gov.br / estadosat / temas.php?sigla=ac\&tema=censodemog2010 relig $>$. Acesso em: 2 jul. 2015.

MORAES, Maria Lygia Quartim de. Usos e limites da categoria gênero. Cadernos PAGU, v. 11, p. 99-105, 1998.

MULHER, LAR \& FAMÍLIA CRISTÃ. Rio de Janeiro: CPAD, ano 1, n. 1, 2000.

. Rio de Janeiro: CPAD, ano 1, n. 5, 2001.

. Rio de Janeiro: CPAD, ano 1, n. 6, 2001.

. Rio de Janeiro: CPAD, ano 4, n. 14, 2003.

. Rio de Janeiro: CPAD, ano 4, n. 15, 2003. 
. Rio de Janeiro: CPAD, ano 4, n. 16, 2003.

. Rio de Janeiro: CPAD, ano 5, n. 23, 2005.

NETO, Ana Luíza Gouvêa. Nacapa e por dentro: uma análise sócio histórica sobre a mulher evangélica em publicações assembleianas. 2015. 148f. Dissertação (Mestrado em Ciência da Religião] - Universidade Federal de Juiz de Fora, Juiz de Fora, 2015.

NOSSO LAR. Rio de Janeiro: CPAD, anol, n. O, dez. 1992.

. Rio de Janeiro: CPAD, ano 3, n. 3, jan./ fev. 1995.

. Rio de Janeiro: CPAD, ano 3, n. 4, mar./abr. 1995.

OLIVEIRA, Adriana Vida de. A teoria de Judith Butler: implicações nas estratégias de luta do movimento feminista. Disponível em: < http:/ / www.neim.ufba.br/site/arquivos/ file/ anais/anaisteoriafeminista.pdf $>$. Acesso em: 7 jun. 2015.

PORCOS e celulares: uma conversa com Marilyn Strather sobre antropologia e arte. Revista PROA, v. 1, n. 2, 2010. Disponível em : < http:// www.ifch.unicamp.br/proa/Entrevistasll/pdfs/strathern.pdf >. Acesso em: 20 jun. 2015.

SABSAY, Leticia Inés. La configuración de identidades como posiciones de sujeito: antiessencialismo y diferencia em Judith Butler. Escritoras y escrituras, n. 5, p. 1-8, 2006. SALES, Léa Silveira. Estruturalismo: história, definições e problemas. Revista de Ciências Humanas, Florianólpolis, n. 13, p. 159 - 188, 2003.

STRATHERN, Marilyn. O gênero da dádiva: problemas com as mulheres e problemas com a sociedade na melanésia. Campinas: Editora UNICAMP, 2006. 